\title{
Outcome of Surgical Treatment in Medically Refractory Epilepsy
}

\author{
Khan $\mathrm{AH}^{1}$, Islam KMT ${ }^{1}$, Barman $\mathrm{KK}^{2}$, Barua $\mathrm{KK}^{1}, \mathrm{Abraham}^{3}$ \\ ${ }^{l}$ Department of Neurosurgery, Bangabandhu Sheikh Mujib Medical University, Dhaka, Bangladesh, \\ ${ }^{2}$ Department of Neurology, Bangabandhu Sheikh Mujib Medical University, Dhaka, Bangladesh, \\ ${ }^{3}$ Department of Neurosurgery, Sree Chitra Tirunal Institute for Medical Science \& Technology, \\ Trivandrum, Kerala, India. \\ Email: fahimshahriyer1@gmail.com
}

\begin{abstract}
The aim of epilepsy surgery is not only to control seizures but also to curtail future adverse neurological sequelae and improve quality of life. Epilepsy surgery is a viable treatment option for selected cases of medically refractory epilepsy. A study was carried out with a series of 34 cases who underwent epilepsy surgery at Sree Chitra Tirunal Institute for Medical Science \& Technology, Kerala, India during July, 2010 to December, 2010. Clinical features, operative procedures and early response to treatment were characterized. Among 34 cases, main clinical manifestation was recurrent seizures. All cases were evaluated by Video Electro Encephalogram (EEG) \& Magnetic Resonance Imaging (MRI) of brain with epilepsy protocol. Nearly 58\% cases were diagnosed as mesial temporal sclerosis who were treated by anterior temporal lobectomy (ATL) with amygdalohippocampectomy (AH). Excision of epileptogenic foci was confirmed by preoperative Electro Cardiogram. Early response to surgery was good. However, a prolonged longitudinal follow up is essential for accurate assessment of seizure outcome.
\end{abstract}

\section{Introduction}

Epilepsy surgery began as removal of gross structural lesions of the brain. With the addition of EEG data from preoperative and intraoperative recordings, areas of removal expanded to include tissue that was grossly normal in appearance but known to give rise to epileptiform activity. ${ }^{1}$

Epilepsy is one of the most common serious neurological conditions. According to a study by the World Health Organization, epilepsy accounts for $1 \%$ of the global burden of disease based on disability-adjusted life-years (DALYs). ${ }^{2}$ In the United States, $80 \%$ of the cost of epilepsy is attributable to patients with medically intractable seizures ${ }^{3}$.

Medically refractory epilepsy is uncontrolled seizures or intolerable side effects of AEDs (Antiepileptic Drugs) interfering with Quality of Life (QoL). About 50 million people suffering from active epilepsy globally. Among them $80 \%$ patients live in resource poor countries. ${ }^{4}$ In India, prevalence 5/1000 and Incidence 5/10,000/year in Bangladesh. Therefore, with population of 150 million prevalence of epilepsy is around 7.5 lacs. ${ }^{5}$ About $20 \%$ patients with active epilepsy are resistant to AED treatment, Nearly 1.5 lac patients in Bangladesh (150 million pop).

Epilepsy constitutes a major public health problem both in developing and developed countries. As many as $70-80 \%$ of persons with newly-diagnosed epilepsy will eventually achieve remission, a majority of them within two years of the onset of epilepsy. About 20-30\% of persons developing epilepsy continue to exhibit chronic recurrent seizures despite optimal treatment with antiepileptic drugs (AEDs). Surgical treatment is an option in selected patients with medically refractory epilepsy. ${ }^{6}$

Mesial temporal sclerosis (MTS) is a common cause of localization-related epilepsy that has been shown to be very amenable to surgery in well-selected cases. ${ }^{7}$ The exact cause of MTS is unknown. The onset in the majority of these patients is in childhood or during adolescence, and approximately one third of patients have a history 
of febrile seizures as children. In many cases, there is good control of the seizures with a single AED for years, which overtime becomes medically intractable. MRI is now very sensitive in showing mesial temporal sclerosis (MTS). Evaluation of MTS or other hippocampal abnormalities is dependent on the radiologist's experience. ${ }^{7-9}$

A study was carried out with three hundred and fifty patients who underwent operation for refractory epilepsy from March 1995 through June 2001. ${ }^{10}$ Medically Refractory Epilepsy, the first comprehensive largely Indian compilation on this subject, ${ }^{11}$ was published in 1999. Epilepsia, the official journal of the International League Against Epilepsy, has recently brought out a supplement on epilepsy surgery in developing countries. $^{12}$

Medically refractory epilepsy patients have to continue lifelong two or more antiepileptic drug which hamper the quality of life and also an economical burden for the society. This study was not done previously in Bangladesh, so Researcher evaluated the outcome of surgical treatment in medically refractory epilepsy patients.

\section{Materials and Methods}

It was a prospective study carried out Department of Neurosurgery in Sree Chitra Tirunal Institute for Medical Science \& Technology, Trivandrum, Kerala, India during the period of July, 2010 to December, 2010. Among 34 cases, main clinical manifestation was recurrent seizures. All cases were diagnosed by Video EEG \& MRI of brain with epilepsy protocol. Patients of epilepsy were evaluated by a comprehensive epilepsy team. Surgery was decided on the basis of electroclinico-radiological evidences. All patients are followed up for six months after surgery.

Data was collected in a pre-designed data collection sheet. Data were analysis using computer based programme statistical social science (SPSS) for windows version 16.

\section{Result}

Total 34 patients were included in this study. The mean age of patients was $21.17 \pm 9.53$ years with age ranged from 6 to 46 years. Males were $64.70 \%$ and females were $35.30 \%$. Highest number of patients $(44.12 \%)$ were in 16 to 30 years of age group (Table I).

Table I: Demographic characteristics of study population $(n=34)$

\begin{tabular}{lll}
\hline \multicolumn{1}{c}{ Age in years } & Number & Percentage $(\%)$ \\
\hline$\leq 15$ years & 11 & 32.35 \\
16-30 years & 17 & 44.12 \\
$>30$ years & 6 & 23.53 \\
Total & 34 & 100 \\
Mean \pm SD & $21.17 \pm 9.53$ \\
Range $\quad$ Sex & $6-46$ \\
& & \\
Male & 22 & 64.70 \\
Female & 12 & 35.30 \\
\hline
\end{tabular}

Mean age of patients was $21.17 \pm 9.53$ years with age ranged from 6 - 46 years. Males were $64.70 \%$ and females were $35.30 \%$

Out of 34 patients, 27 patients (44.12\%) presented with complex partial seizure (Table II).

Table II: Diagnosis

\begin{tabular}{lll}
\hline \multicolumn{1}{c}{ Type of lesion } & Number & Percentage (\%) \\
\hline $\begin{array}{l}\text { Medical temoporal } \\
\text { sclerosis (MTS) }\end{array}$ & 20 & 58.82 \\
$\begin{array}{l}\text { Insuloputamental } \\
\text { cavernoma }\end{array}$ & 1 & 2.94 \\
$\begin{array}{l}\text { Post-operative subgaleal } \\
\text { collection with fever }\end{array}$ & 1 & 2.94 \\
$\begin{array}{l}\text { Post parietal calcified mass } \\
\text { Hemispheric }\end{array}$ & 1 & 2.94 \\
$\begin{array}{l}\text { Ganglioglioma } \\
\text { Perisylvian \& parieto }\end{array}$ & 1 & 5.88 \\
$\begin{array}{l}\text { occipital gliosis } \\
\text { Frontal gliosis }\end{array}$ & 1 & 2.94 \\
$\begin{array}{l}\text { Hypothalmic hematoma } \\
\text { Extra temporal }\end{array}$ & 1 & 2.94 \\
$\begin{array}{l}\text { Failed callosotomy } \\
\text { Right and left occipital } \\
\text { gliosis }\end{array}$ & 1 & 2.94 \\
$\begin{array}{l}\text { Occipital congenital } \\
\text { dysplasia, gliosis }\end{array}$ & 1 & 2.94 \\
Total & 1 & 2.94 \\
\hline Out of 34 patient, & 34 & 100
\end{tabular}

Out of 34 patients, diagnosis of 20 patients (58.82\%) were mesial temporal sclerosis.

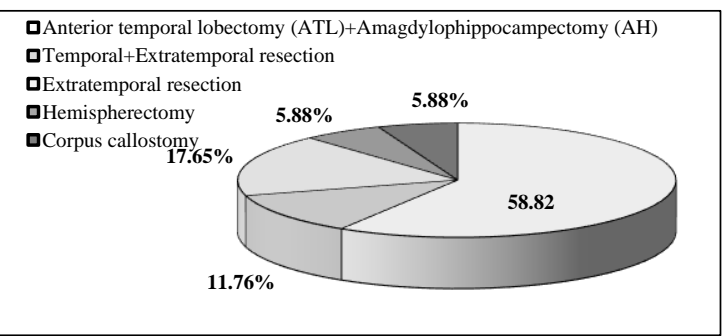

Fig. 1: Operation done 
Out of 34 patients, anterior temporal lobectomy \& amygdalohippocampectomy was done in 20 (58.82\%) patients (Fig. 1).

After six months follow up among 34 patients 19 $(55.88 \%)$ were seizure free after epilepsy surgery (Table III).

Table III: Outcome of epilepsy surgery (after six months follow up)

\begin{tabular}{lll}
\hline \multicolumn{1}{c}{ Results } & \multicolumn{1}{c}{ Number } & Percentage (\%) \\
\hline Seizure free & 19 & 55.88 \\
Improved & 10 & 29.41 \\
Not improved & 3 & 8.82 \\
Surgery postponed & 1 & 2.94 \\
due bleeding & & 2.94 \\
Death & 1 & 100.00 \\
Total & 34 & \\
\hline
\end{tabular}

Nineteen (19) patients (55.88\%) were seizure free was 34 patients who underwent epilepsy surgery.

\section{Discussion}

In this series most common indication for epilepsy surgery is mesial temporal sclerosis. Passario et al. ${ }^{13}$ reported mesial temporal scleroses are the most common indication for epilepsy surgery in adults, accounting for $75 \%$ of cases in adult surgical series.

In adults, the most common surgical procedure for temporal lobe epilepsy (TLE) involves the medial temporal lobe either an amygdalohippocampectomy (resection of the amygdala, hippocampal head and body, and adjacent Para hippocampal gyrus) or an anteromedial temporal resection that also includes resection of the anterior, inferior, and middle temporal gyri (3-4 $\mathrm{cm}$ from the temporal tip). In children, cortical dysplasia and tumors are the most common etiologies, with percutaneous disorders (i.e., tuberous sclerosis, Sturge Weber syndrome), hemispheric syndromes (Rasmussen syndrome, hemimegalencephaly), perinatal epileptic encephalopathies, hypothalamic hamartomas, and mesial temporal sclerosis being less common. ${ }^{13}$

Respective surgery in children often involves resection of lesions, such as malformations of cortical development (i.e. cortical dysplasia), hamartomas, developmental tumors, or lesions associated with perinatal, hypoxic, ischemic injury.

This study found $55.8 \%$ of seizure free, $29.45 \%$ were improved and $8.82 \%$ had no improvement.
In a randomized, controlled, intent-to-treat trial comparing epilepsy surgery with medical treatment, Wieser et al. ${ }^{14}$ found that at the end of one year, $58 \%$ of patients in the surgical group were free from disabling seizures, and 10-15\% had no improvement.

Epilepsy surgery is emerging subspecialty with good outcome. This study also showed that Quality of Life (QoL) at one year was significantly improved in the surgical group. Morbidity was minimal. However, one patient died but one operation postponed due to sinus injury and profuse bleeding.

Spencer reported the 2-10 years' outcome in 226 patients who underwent epilepsy surgery. ${ }^{15}$ They divided the seizure-free outcome into pathologic subgroups: glioma (70\%), developmental (58\%), vascular $(60 \%)$, and mesial temporal sclerosis $(67 \%)$. A systematic review and meta-analysis by Engel et al that included 32 studies and 2,250 patients showed that $63 \%$ of patients remained seizure free after 2-5 years of follow-up. ${ }^{16}$

In retrospective review of 143 patients with malformations of cortical development, sustained overall rates of seizure control were demonstrated in $72 \%$ at two years, $65 \%$ at five years, and $67 \%$ at 10 years. Complete resection of electrocardiographic and anatomic abnormalities was most predictive of seizure-free outcome. ${ }^{17}$

\section{Acknowledgement}

We could carry out this project by a liberal fund from Bangladesh Medical Research Council. So many thanks to BMRC authority. Special thanks to the administrative authority, staffs of different categories of the department of surgical oncology of National Institute of Cancer Research \& Hospital, Dhaka for their kind support and cooperation to finish this tedious job.

\section{References}

1. Ries LAG, Eisner MP, Kosary CL, et al. (eds): SEER Cancer Statistics Review, 1975-2000. Bethesda, MD, National Cancer Institute, 2003. http://seer.cancer.gov/csr/1975_2000.

2. Mullan F: Re-entry: The educational needs of the cancer survivor. Health Educ Q 10:88-94, 1984 (suppl.)

3. Mullan F: Seasons of survival: Reflections of a physician with cancer. N Engl J Med 1985; 313: 27073. 
4. cKinley ED: Under toad days: Surviving the uncertainty of cancer recurrence. Ann Intern Med 2000; 133:479-80.

5. Degner LF, Kristjanson LJ, Bowman D, Sloan JA, Carriere $\mathrm{KC}$, O'Neil J, et al.: Information needs and decisional preferences in women with breast cancer. JAMA 1997; 277: 1485-92.

6. Burstein HJ, Winer EP. Primary care for survivors of breast cancer. N Engl J Med 2000; 343: 1086-94.

7. Ganz PA. Impact of quality of life outcomes on clinical practice. Oncology. 1995; 9:61-65.

8. Hartl K, Rebecca S, Marianne M, Jutta E, Hans R, Harald S, et al. Quality of Life, Anxiety, and Oncological Factors: A Follow-Up Study of Breast Cancer Patients. Psychosomatics 2010; 51:112-23.

9. Stewart BW, Paul Kleihues P: World Cancer Report. Lyon, France, International Agency Research on Cancer; 2003.

10. Montazeri A. Health-related quality of life in breast cancer patients: A bibliographic review of the literature from 1974 to 2007. J Experim Clin Cancer Res 2008, 27:32.

11. Eifel P, Axelson JA, Costa J, Crowley J, Curran WJ Jr, Deshler A, et al. National Institutes of Health Consensus Development Conference Statement: adjuvant therapy for breast cancer, November 1-3, 2000. J Natl Cancer Inst 2001; 93:979-89.
12. National Center for Health Statistics CDCP. US Mortality Public Use Data Tapes, 1969-2003. 2006.

13. American Cancer Society ISDH., Indiana Cancer Consortium Indiana Cancer Facts and Figures 2006: A sourcebook for planning and implementing programs for cancer prevention and control. 2006.

14. Collaborative Group on Hormonal Factors in Breast Cancer. Breast cancer and hormone replacement therapy: collaborative reanalysis of data from 51 epidemiological studies of 52705 women with breast cancer and 108411 women without breast cancer. Lancet 1997; 350: 1047-59.

15. Hartl K, Schennach R, Muller M, Engel J, Reinecker $\mathrm{H}$, Sommer H, et al.: Quality of Life, Anxiety, and Oncological Factors: A Follow-Up Study of Breast Cancer Patients. Psychosomatics 2010; 51:112-23.

16. Mehnert A, Koch U: Prevalence of acute and posttraumatic stress disorder and comorbid mental disorders in breast cancer patients during primary cancer care: a prospective study. Psycho-Oncology 2007; 16:181-88.

17. Millar K, Purushotham AD, McLatchie E, George WD, Murray GD: A 1-year prospective study of individual variation in distress, and illness perceptions, after treatment for breast cancer. J Psychosom Res 2005; 58:335-42. 